\title{
Optimization of Machining Parameters of Aluminum Alloy BS-1474 2014 A using Response Surface Methodology
}

waqas javaid ( $\square$ waqas_wec@hotmail.com )

university of Engineering and Technology, Taxila https://orcid.org/0000-0002-0800-719X

Tauqeer Iqbal

National University of Science and technology, islamabad

Ammar ul Hassan

university of engineering and technology taxila

\section{Original Article}

Keywords: Surface Roughness, Metal Removal Rate, Turning, Response Surface Methodology, Aluminum Alloy, Tool-Chip Interface temperature

Posted Date: April 27th, 2020

DOl: https://doi.org/10.21203/rs.3.rs-21530/v1

License: (a) (1) This work is licensed under a Creative Commons Attribution 4.0 International License. Read Full License 


\title{
Optimization of Machining Parameters of Aluminum Alloy BS-1474 2014 A using Response Surface Methodology
}

Waqas Javaid ${ }^{1}$, Tauqeer Iqbal ${ }^{2}$, Ammar ul Hassan ${ }^{1}$

${ }^{1}$ University of Engineering and Technology, Taxila, Pakistan.

${ }^{2}$ National University of Science and Technology, Islamabad, Pakistan.

\begin{abstract}
High surface quality, optimum Material Removal Rate (MRR) and Tool-Chip Interface temperature $\left(\mathrm{T}_{\mathrm{c}}\right)$ have significant importance in machining process. Similarly, dimensional accuracy in machining process also relies heavily on machining parameters. In machining operations, there are a number of parameters which have direct or indirect effect on the Surface Roughness ( $\mathrm{Ra}$ ) and MRR of the product. The surface roughness and MRR in turning process are affected by spindle speed (SS), feed rate (FR) and depth of cut (DOC). The optimization of turning parameters will be very helpful in improving quality of manufacturing and machining cost. In order to have an improved product, extensive research has been carried out to optimize machining process. The current research is focused at Response Surface Methodology (RSM) of turning process of Aluminum alloy (BS-1474 2014 A) by using variable sets of machining parameters i.e., SS, FR and DOC with carbide tipped tool. Multiple experiments were performed on CNC Lathe machine by using different combinations of process parameters. Response surface methodology was applied to reach theoretical values of the responses parameters (i.e, Ra, MRR, $\mathrm{T}_{\mathrm{c}}$ ) and an agreement was observed between actual machining results and methodology values. Design Expert-7 was used as a statistical tool to come to a conclusion on whether achieved results are optimum for turning process or otherwise. For a close correlation, comparison between hypothetical and investigational data is also the part of this research. Significant agreement between theoretically optimized machining parameters and experimental data has been observed.
\end{abstract}

Key words: Surface Roughness, Metal Removal Rate, Turning, Response Surface Methodology, Aluminum Alloy, Tool-Chip Interface temperature. 


\section{Introduction}

Good surface finish, Low Tool-Chip Interface temperature and optimum value of MRR during machining has an important part to play in ensuring dimensional accuracy and productivity. Therefore, selection of optimum machining parameters is a paramount to achieve the highest values of response parameters (i.e, Ra, MRR, Tc). Response surface methodology can be a vital tool in selection of optimum set of values for response parameters. In this research, a mathematical model is developed with the help of RSM to predict the Ra and MRR. The mathematical model with the help of regression method is developed by using experimental data. ANOVA is employed for the validation of the results. The optimizing procedure of RSM is applied for the responses of Ra and MRR by use of input parameters of SS, FR and DOC.

In [1] authors investigated the effect of cutting edge geometry, hardness of the work piece surface and cutting conditions on the Ra and cutting forces in AISI H13 steel and concluded that geometry of cutting edge has considerable effect on Ra. In [2] authors used RSM method for mild steel for the prediction of Ra while using cutting tool of Tin-coated Tungsten Carbide (CNMG). The author used Genetic Algorithm (GA) for the prediction of Ra. In [3] authors used Taguchi technique to predict the Ra and established a correlation of Ra with FR, speed of cutting and DOC using linear regression model. In [4] authors used non-linear regression technique to predict the values of $\mathrm{Ra}$ and after prediction compared them with the available models in literature.

In [5] authors presented a model for measurement of Ra of turned parts by the use of computer vision and concluded that the developed system was faster, cheaper and very useful for the measurement of Ra in manufacturing system. In [6] authors developed a model to measure the effect of turning parameters on the Ra of AISI 410 steel. The author used RSM and concluded that FR is the main factor that controls the $\mathrm{Ra}$ such as with the increase in FR Ra increases and vice versa. In [7] authors used Taguchi technique by using four input cutting parameters (i.e, FR, cutting speed, DOC and cutting tool nose run-off) to predict Ra and ratio of tool wear by using CNC machine and comparison with the bench-mark parameters is carried out. In [8] authors used the combination of Fuzzy Logic System through Adaptive Neuro-Fuzzy Interference System (ANFIS) and RSM techniques to compute the Ra of Titanium Alloy (Ti6Al4V) and concluded that ANFIS measured that results with less error. 
In [9] authors used experimental technique by using parameters of cutting speed, FR, DOC, tool flank wear and vibration of cutting tool on Ra of Ti-6Al-4V and concluded that vibration of cutting tool has significant effect of Ra. Secondly, the vibration of cutting tool is lower at high cutting speed. In [10] authors stated that RSM and Taguchi are methods used most for the measuring responses of machining and also stated that the most important factor for the lower Ra is FR whereas for MRR, FR and cutting depth are the significant parameters. In [11] authors established data at Aluminum material AA6061. The authors examined the responses of $\mathrm{Ra}$, cutting force and consumption of power with the help of machining parameters of FR, DOC and spindle speed by using multiple regression model. In [12] authors established study of two types of work-pieces (Aluminum Alloy and resin) by using the RSM and Design Expert-8 software. The author analyzed the responses of MRR and $\mathrm{Ra}$ and summarized the optimum parameters to compute the performance.

In [13] authors analyzed the Ra on the milling of hardened steel by using Taguchi method and ANOVA Technique. The study also provides the role of each machining parameter and their interface for Ra. In [14] authors used FR, SS, DOC and angle of cut as machining parameters to measure the responses of pressure and voltage of CNC turning machine by using RSM and Taguchi method in order to find the optimum machining parameters. In [15] authors used multiobjective GA by using FR, SS and DOC as machining parameters to predict the Ra on NC milling machine. In [16] authors integrated the techniques of GA, RSM and Desirability Function (DF) to measured the optimum machining parameters for minimum value of Ra. In [17] authors used multi-objective optimization GA and RSM to predict the optimum parameters of minimum lubricant quantity, $\mathrm{Ra}$ and power consumption for milling operation of AISI-1045 steel. In [18] authors used multi-objective GA by using radial depth of cut, axial depth of cut and helical angle to depict the MRR and cutting force on high speed milling machine. In [19] authors depict the various characteristic of Ra on milling of AISI4140 steel by using the controlling factors of SS, FR, DOC and number of inserts. The authors used multi-objective Taguchi Technique in this research for the prediction of optimal parameters. In [20] authors used Taguchi method to predict the responses of Ra, cutting force and wear of tool for both coated and un-coated carbide tips by response optimization methods to suggest the optimal parameters for machining of Inconel 718. 
Considerable development in similar mathematical modeling has been reported by various authors. The work has however been mainly related to ferrous metal. The current work investigates a non-ferrous Aluminum alloy BS-1474 2014 A with a turning process using nonferrous grade carbide tipped tool and a tool holder. The grade of Aluminum alloy investigated in current work has been extensively used in various defense and aerospace industries around the world. Optimization of involved machining parameters therefore can pave way for an improved and cost effective machining with dimensional accuracy.

\section{Experimental Procedure}

Aluminum Alloy grade BS-1474 2014 A has been used in current work using CNC turning process. A round bar of $40 \mathrm{~mm}$ diameter of Aluminum Alloy (composition shown in Table 1) is used is this experiment and responses of Ra, MRR and cutting tool tip temperature is measured on CNC turning machine. The detail of material and cutting tip is as under:-

Material: BS-1474 2014 A

Cutting Tip: DCGX 11 T3 04-AL (Carbide Tip of radius $02 \mathrm{~mm}$ )

Tool holder: PDJNR-L 2020K-11

\begin{tabular}{|l|c|c|c|c|c|c|c|}
\hline \multicolumn{2}{|l|}{ Table \#1:- Composition of BS-1474 2014 A T6 } \\
\hline Element & $\mathrm{Cu}$ & $\mathrm{Mn}$ & $\mathrm{Cr}$ & $\mathrm{Ni}$ & $\mathrm{Zn}$ & $\mathrm{Si}$ & $\mathrm{Fe}$ \\
\hline $\begin{array}{l}\text { Content } \\
(\%)\end{array}$ & $3.8-5.0$ & $0.40-1.2$ & 0.10 & 0.10 & 0.25 & $50-$ & 0.50 \\
\end{tabular}

\subsection{Experimental Design}

20 specimens were turned using CNC machine with range of spindle speed between 900 RPM to 1400 RPM. Similarly, Feed Rate (per Rev) and Depth of Cut (mm) were varied between 0.025 to 0.15 and 0.8 to 1.4 respectively. Machining of specimen was carried out using same cutting tool geometry, carbide tip and tool holder. Specimen machining combinations with responses resulted into 150 different experiments on a work piece of $31.5 \mathrm{~mm}$ length. Tool chip interface temperature was measured by using Infrared thermometer gun model UT 300C. Surface roughness was measured using Hommel tester. 


\section{Results \& Discussion}

Machining parameters as inputs were deduced by using Design Expert-7. Values of input machining parameters involving spindle speed, feed rate and depth of cut were applied in experimental procedure of machining. Achieved results of material removal rate, tool chip interface temperature and surface roughness are presented in table 2 below. The results indicate a correlation between spindle speed and material removal rate. Material removal rate has been found to have a direct correlation with spindle speed. Similarly, a direct relation between spindle speed and Tc can be seen. Surface roughness on the contrary has been reduced as a result of high spindle speeds. The results are in agreement with previously available literature on metal machining.

Table 2: Machining Input Parameters and Output for 20 specimen

\begin{tabular}{|c|c|c|c|c|c|c|}
\hline \multirow{2}{*}{ Test No. } & \multicolumn{3}{|c|}{ Inputs } & \multicolumn{3}{c|}{ Outputs } \\
\cline { 2 - 7 } & $\mathbf{S S}$ & $\mathbf{F R}(\mathbf{m m})$ & $\mathbf{D O C}$ & $\mathbf{M R R}$ & $\left.\mathbf{T}_{\mathbf{c}} \mathbf{}^{\mathbf{}} \mathbf{C}\right)$ & $\mathbf{R a}$ \\
\hline 1 & 900 & 0.02 & 0.8 & 1.20 & 17.2 & 2.350 \\
\hline 2 & 1400 & 0.02 & 0.8 & 3.28 & 22.4 & 1.507 \\
\hline 3 & 900 & 0.15 & 0.8 & 7.01 & 20.0 & 2.460 \\
\hline 4 & 1400 & 0.15 & 0.8 & 7.86 & 20.6 & 2.360 \\
\hline 5 & 900 & 0.02 & 1.4 & 1.25 & 18.4 & 2.910 \\
\hline 6 & 1400 & 0.02 & 1.4 & 2.20 & 19.9 & 2.916 \\
\hline 7 & 900 & 0.15 & 1.4 & 8.68 & 25.0 & 3.520 \\
\hline 8 & 1400 & 0.15 & 1.4 & 10.00 & 20.5 & 3.340 \\
\hline 9 & 729 & 0.09 & 1.1 & 3.71 & 21.5 & 2.510 \\
\hline 10 & 1570 & 0.09 & 1.1 & 6.69 & 24.5 & 1.890 \\
\hline 11 & 1150 & 0.02 & 1.1 & 0.25 & 14.6 & 3.290 \\
\hline 12 & 1150 & 0.19 & 1.1 & 9.62 & 18.9 & 3.480 \\
\hline 13 & 1150 & 0.09 & 0.6 & 5.13 & 19.8 & 1.695 \\
\hline 14 & 1150 & 0.09 & 1.6 & 5.30 & 20.8 & 2.980 \\
\hline 15 & 1150 & 0.09 & 1.1 & 0.39 & 18.8 & 1.870 \\
\hline 16 & 1150 & 0.09 & 1.1 & 0.39 & 18.8 & 1.870 \\
\hline 17 & 1150 & 0.09 & 1.1 & 0.44 & 19.0 & 1.850 \\
\hline 18 & 1150 & 0.09 & 1.1 & 0.42 & 18.8 & 1.870 \\
\hline 19 & 1150 & 0.09 & 1.1 & 0.44 & 19.0 & 1.860 \\
\hline 20 & 1150 & 0.09 & 1.1 & 0.42 & 19.1 & 1.870 \\
\hline
\end{tabular}

Surface roughness as per table 2 above; have been observed to improve with enhanced spindle speeds. Combinations of spindle speed, feed rate and depth of cut were obtained through Design Expert-7. Each permutation has been reported in terms of achieved machining output. The combination of best surface finish, minimum tip chip interface temperature and material removal rate have been selected for optimum machining variables. 
In order to measure the statistical significance, analysis of variance (ANOVA) is used and results for the Ra, MRR and $\mathrm{T}_{\mathrm{c}}$ are tabulated in Table 3, 4 and 5 respectively. The degree of freedom (df) linked to every machining parameter is measured for each response and then accordingly p-values are measured. It is worth mentioning that lower p-value specify the statistical significant of the consequent response.

Table 3: ANOVA Table for Ra

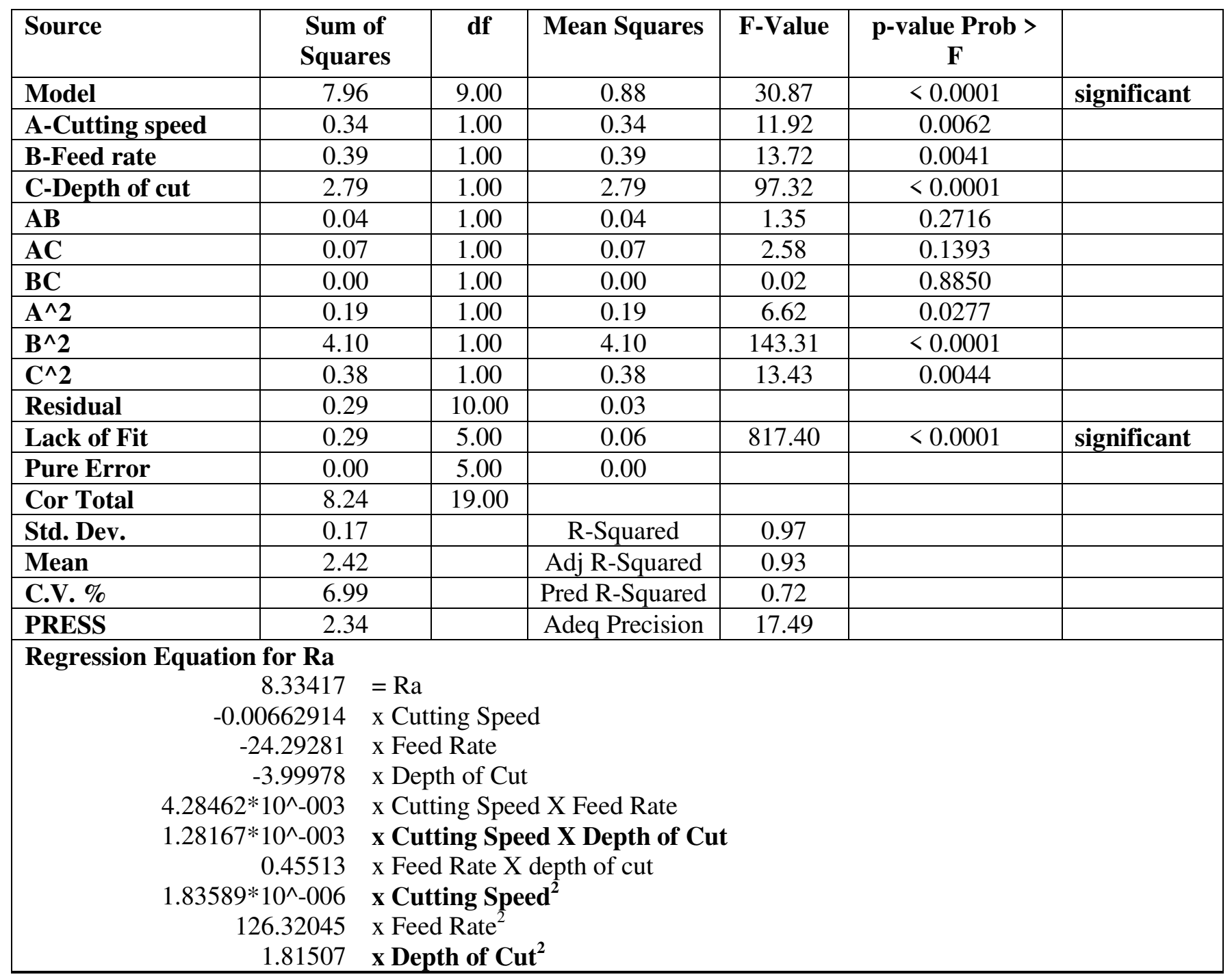

Derived results from above table indicate a significant combination of input machining parameters. Similarly, table 4 and 5 indicate significant result with input machining variables. 
Table 4: ANOVA Table for MRR

\begin{tabular}{|c|c|c|c|c|c|c|}
\hline Source & $\begin{array}{c}\text { Sum of } \\
\text { Squares }\end{array}$ & df & Mean Squares & F-Value & $\begin{array}{c}\text { p-value Prob > } \\
\text { F }\end{array}$ & \\
\hline Model & 231.06 & 9.00 & 25.67 & 169.29 & $<0.0001$ & significant \\
\hline A-Cutting speed & 7.63 & 1.00 & 7.63 & 50.34 & $<0.0001$ & \\
\hline B-Feed rate & 125.37 & 1.00 & 125.37 & 826.67 & $<0.0001$ & \\
\hline C-Depth of cut & 0.69 & 1.00 & 0.69 & 4.58 & 0.0581 & \\
\hline$\overline{A B}$ & 0.09 & 1.00 & 0.09 & 0.61 & 0.4512 & \\
\hline $\mathbf{A C}$ & 0.05 & 1.00 & 0.05 & 0.35 & 0.5670 & \\
\hline BC & 2.93 & 1.00 & 2.93 & 19.29 & 0.0014 & \\
\hline$A^{\wedge} 2$ & 39.05 & 1.00 & 39.05 & 257.50 & $<0.0001$ & \\
\hline $\mathbf{B}^{\wedge} 2$ & 34.70 & 1.00 & 34.70 & 228.83 & $<0.0001$ & \\
\hline $\mathrm{C}^{\wedge} 2$ & 39.23 & 1.00 & 39.23 & 258.68 & $<0.0001$ & \\
\hline Residual & 1.52 & 10.00 & 0.15 & & & \\
\hline Lack of Fit & 1.51 & 5.00 & 0.30 & 805.71 & $<0.0001$ & significant \\
\hline Pure Error & 0.00 & 5.00 & 0.00 & & & \\
\hline Cor Total & 232.58 & 19.00 & & & & \\
\hline Std. Dev. & 0.39 & & R-Squared & 0.99 & & \\
\hline Mean & 3.73 & & Adj R-Squared & 0.99 & & \\
\hline C.V. \% & 10.43 & & Pred R-Squared & 0.95 & & \\
\hline PRESS & 12.01 & & Adeq Precision & 37.01 & & \\
\hline \multicolumn{7}{|c|}{ Regression equation for MRR } \\
\hline & 52.73948 & \multicolumn{5}{|l|}{$=\mathrm{MRR}$} \\
\hline & -0.055827 & \multicolumn{5}{|c|}{ x Cutting Speed } \\
\hline & -42.30194 & \multicolumn{5}{|c|}{ x Feed Rate } \\
\hline & -40.96562 & \multicolumn{5}{|c|}{ x Depth of Cut } \\
\hline & -0.00664234 & \multicolumn{5}{|c|}{ x Cutting Speed x Feed Rate } \\
\hline & -0.00108683 & \multicolumn{5}{|c|}{$\mathrm{x}$ Cutting Speed $\mathrm{x}$ Depth of Cut } \\
\hline & 31.0126 & \multicolumn{5}{|c|}{$\mathrm{x}$ Feed Rate $\mathrm{x}$ depth of cut } \\
\hline & $2.63383 \mathrm{E}-05$ & \multicolumn{5}{|c|}{ x Cutting Speed ${ }^{2}$} \\
\hline & 367.29386 & \multicolumn{5}{|c|}{ x Feed Rate ${ }^{2}$} \\
\hline & 18.33229 & \multicolumn{5}{|c|}{ x Depth of $\mathrm{Cut}^{2}$} \\
\hline
\end{tabular}


Table 5: ANOVA Table for $T_{c}$

\begin{tabular}{|c|c|c|c|c|c|c|}
\hline Source & $\begin{array}{l}\text { Sum of } \\
\text { Squares }\end{array}$ & $\mathrm{df}$ & Mean Squares & $\begin{array}{c}\text { F- } \\
\text { Value }\end{array}$ & $\begin{array}{c}\mathrm{p} \text {-value } \\
\text { Prob }>\mathrm{F}\end{array}$ & \\
\hline Model & 100.02 & 9.00 & 11.11 & 51.67 & $<0.0001$ & significant \\
\hline A-Cutting speed & 4.51 & 1.00 & 4.51 & 20.95 & 0.0010 & \\
\hline B-Feed rate & 17.44 & 1.00 & 17.44 & 81.07 & $<0.0001$ & \\
\hline C-Depth of cut & 2.04 & 1.00 & 2.04 & 9.50 & 0.0116 & \\
\hline AB & 14.05 & 1.00 & 14.05 & 65.30 & $<0.0001$ & \\
\hline$\overline{A C}$ & 9.68 & 1.00 & 9.68 & 45.01 & $<0.0001$ & \\
\hline BC & 4.81 & 1.00 & 4.81 & 22.34 & 0.0008 & \\
\hline$A^{\wedge} 2$ & 33.81 & 1.00 & 33.81 & 157.18 & $<0.0001$ & \\
\hline$\overline{B^{\wedge} 2}$ & 6.63 & 1.00 & 6.63 & 30.81 & 0.0002 & \\
\hline $\mathrm{C}^{\wedge} 2$ & 4.80 & 1.00 & 4.80 & 22.31 & 0.0008 & \\
\hline Residual & 2.15 & 10.00 & 0.22 & & & \\
\hline Lack of Fit & 2.06 & 5.00 & 0.41 & 23.35 & 0.0018 & significant \\
\hline Pure Error & 0.09 & 5.00 & 0.02 & & & \\
\hline Cor Total & 102.17 & 19.00 & & & & \\
\hline Std. Dev. & 0.46 & & R-Squared & 0.98 & & \\
\hline Mean & 19.88 & & Adj R-Squared & 0.96 & & \\
\hline C.V. \% & 2.33 & & Pred R-Squared & 0.84 & & \\
\hline PRESS & 16.15 & & Adeq Precision & 28.64 & & \\
\hline \multicolumn{7}{|c|}{ Regression equations for temp: } \\
\hline & $\begin{array}{r}29.56349 \\
-0.031001 \\
94.72052 \\
0.67327 \\
-0.081538 \\
-0.014667 \\
39.74359 \\
-2.4505 \mathrm{E}-05 \\
-160.50135 \\
6.41107\end{array}$ & \multicolumn{5}{|c|}{$\begin{array}{l}=\mathrm{T}_{\mathrm{C}} \\
\text { x Cutting Speed } \\
\text { x Feed Rate } \\
\text { x Depth of Cut } \\
\text { x Cutting Speed X Feed Rate } \\
\text { x Cutting Speed X Depth of Cut } \\
\text { x Feed Rate X depth of cut } \\
\text { x Cutting Speed } \\
\text { x Feed Rate } \\
\text { x Depth of Cut }\end{array}$} \\
\hline
\end{tabular}

Effect of depth of cut (DOC) and cutting speed (SS) on surface roughness (Ra) have been analyzed by using 3-dimensional graphs in Design Expert Software-7.0. These graphs (shown in figures 1-9) show the graphical overview of the effects of input parameters i.e, SS, FR and DOC on the Ra, MRR and $\mathrm{T}_{\mathrm{c}}$. Figure 1 shows the effect DOC and SS on Ra. At higher value of DOC, effect of Ra is high; whereas, at low SS the effect of $\mathrm{Ra}$ is higher. The figure 2 demonstrates the effect of FR and SS on Ra. At the middle level of FR, the values of Ra are smaller. 


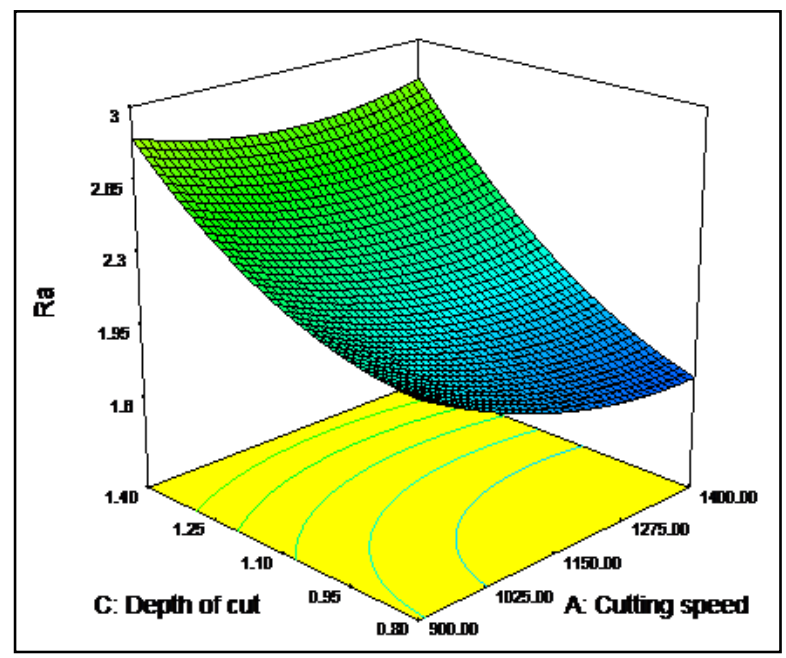

Fig. 1: Effect of DOC and SS on Ra

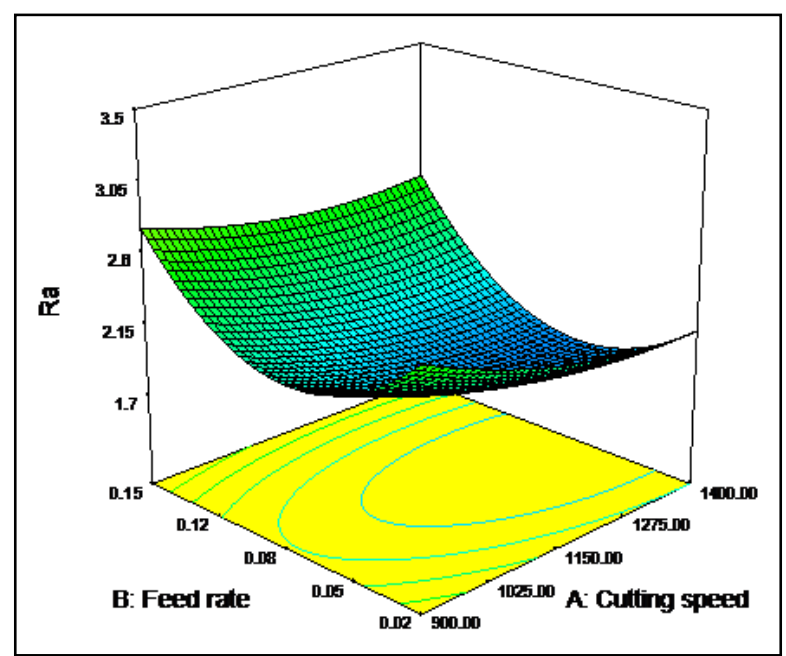

Fig. 2: Effect of FR and SS on Ra

Figure 3 shows the effect of DOC and FR on Ra.The values are lower at the middle of the graph. The figure 4 shows the effect of DOC and SS on MRR. At the high values of DOC and $\mathrm{SS}$, the MRR values are higher. The curvature at the center shows that MRR values at the middle of the graph are low.

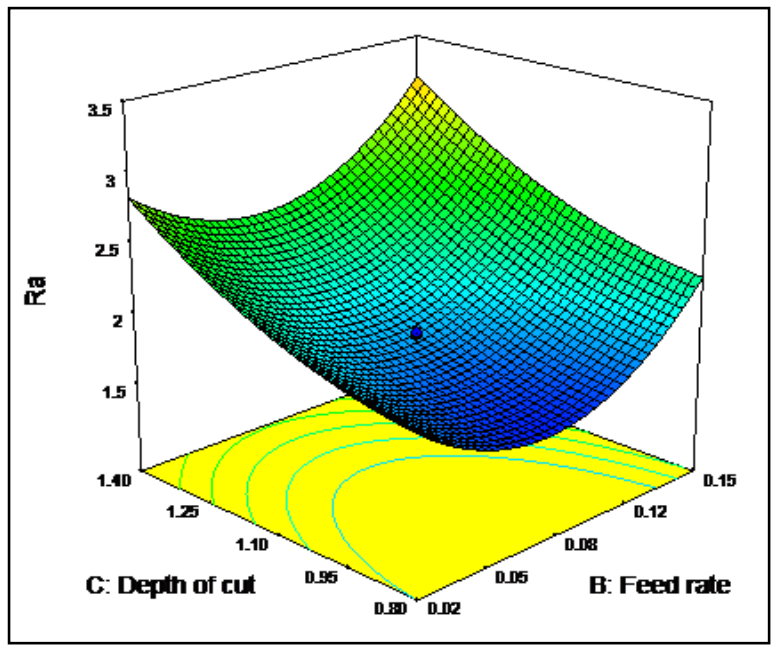

Fig. 3: Effect of DOC and FR on Ra

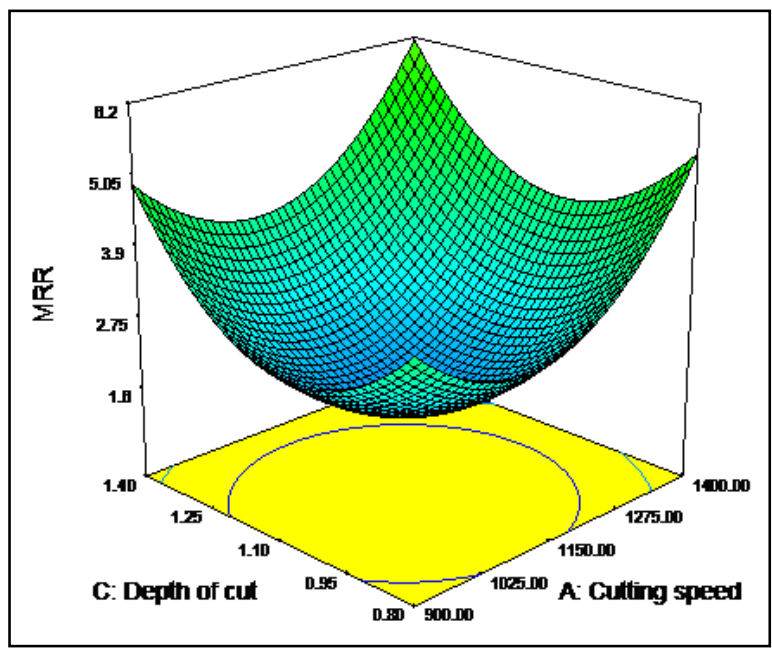

Fig. 4: Effect of DOC and SS on MRR

Figure 5 demonstrates the effect of FR and SS on MRR. The figure 6 represents the effect of DOC and Fr on MRR. Similarly, figures 7, 8, and 9 demonstrate the effect of FR and SS, $\mathrm{DOC}$ and $\mathrm{FR}$, and DOC and $\mathrm{SS}$ on the $\mathrm{T}_{\mathrm{c}}$ respectively. 


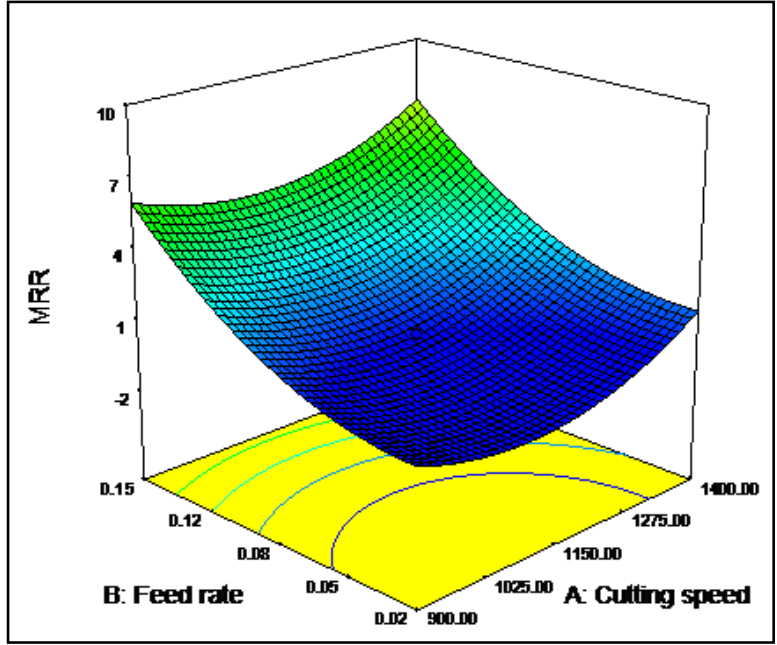

Fig. 5: Effect of FR and SS on MRR

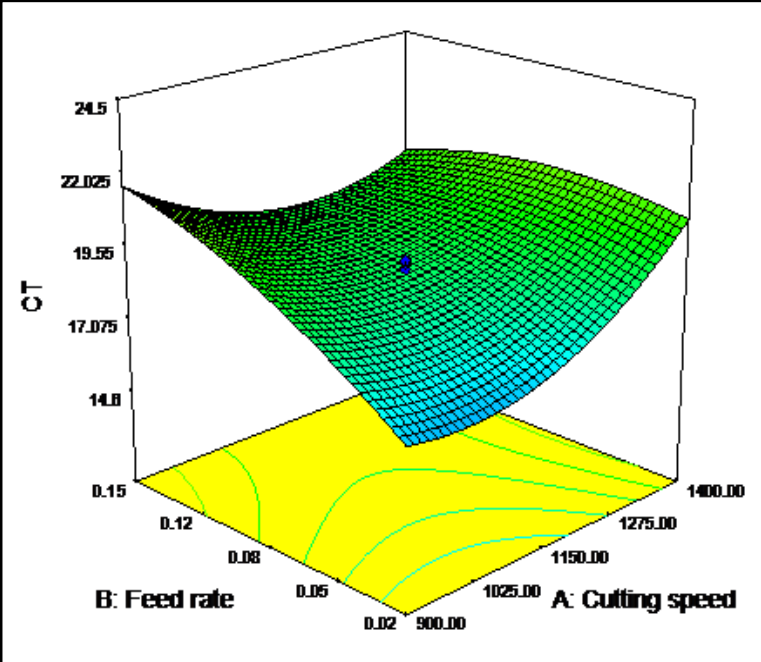

Fig. 7: Effect of FR and $S S$ on $T_{c}$

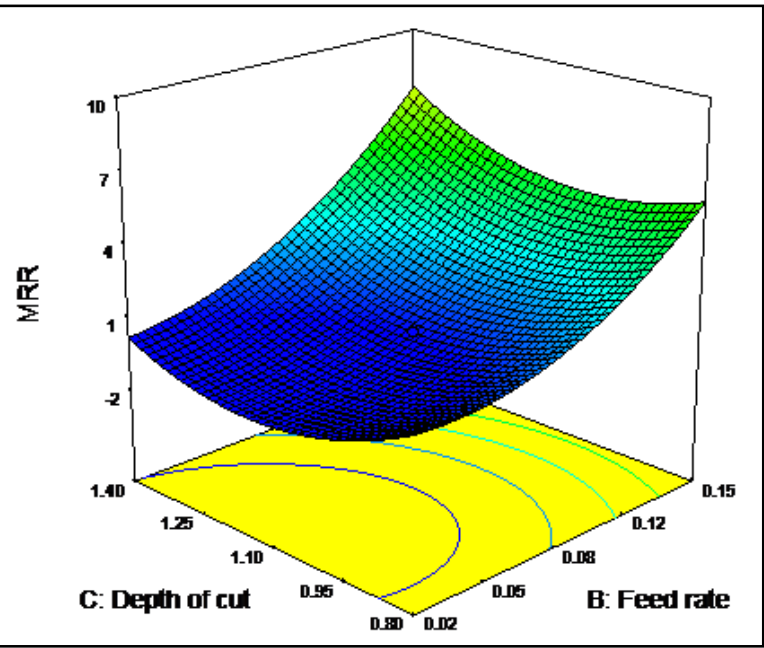

Fig. 6: Effect of DOC and FR on MRR

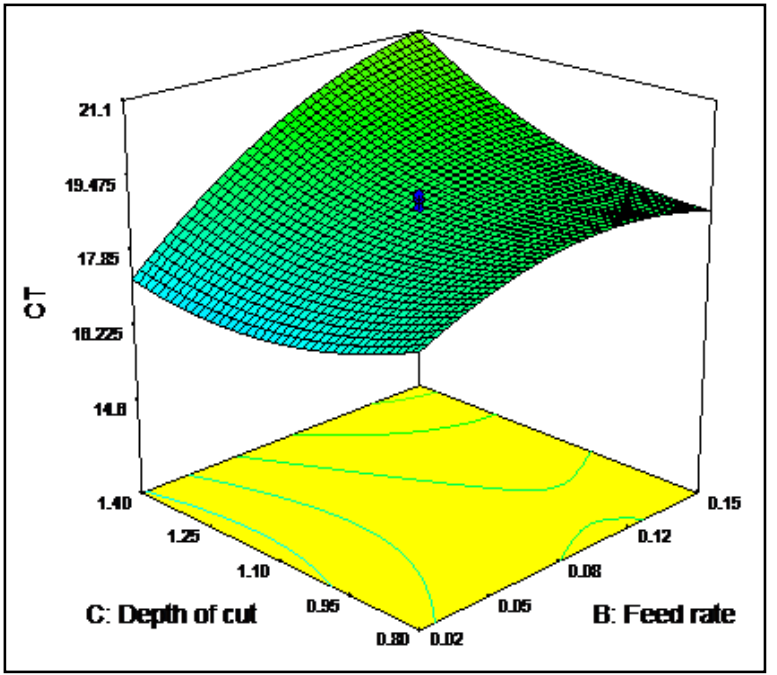

Fig. 8: Effect of DOC and FR on $T_{C}$

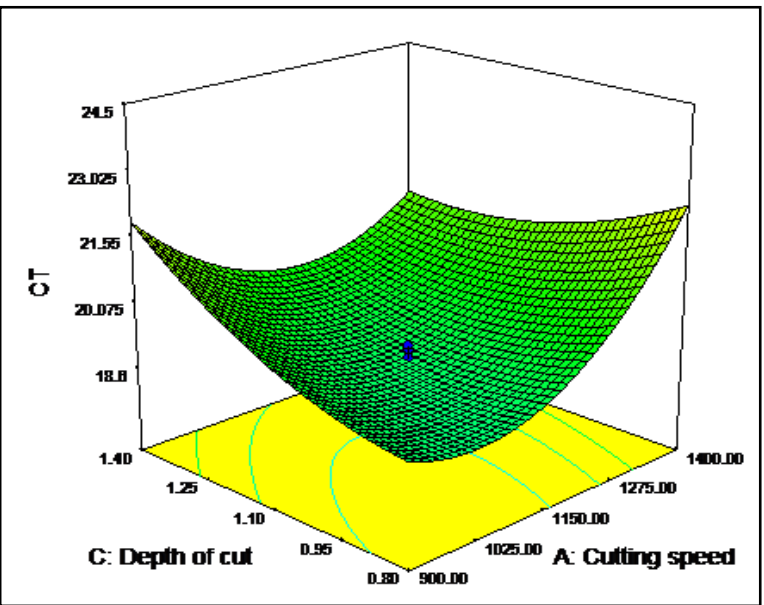

Fig. 9: Effect of DOC and FR on $T_{C}$ 


\section{Conclusions:}

The main objective of this research was to identify the optimum parameters for the maximum value of MRR, minimum value of Ra and $T_{c}$. The RSM method was used for the investigation and assessment of the responses by using quadratic model. The results are summarized as follows:-

- Machining parameters optimization for Aluminum alloy has been found to have strong correlation with SS, FR and DOC.

- Tool chip interface has been found to be affected both by feed rate and depth of cut. The $\mathrm{Ra}$ is found to be affected by spindle speed.

- Spindle speed has been found to affect material removal rate, tool chip interface temperature and material removal rate.

- Better surface finish has been observed by enhancing spindle speeds. At higher speeds, however, Tc has been found to be on the rise.

- Similar affect has been observed with Material removal rate where, higher depth of cut induced higher MRR and lower values of MRR have been seen with lower values of DOC.

- The selected parameters: SS, FR and DOC have dominating effect on Ra and MRR.

- The obtained results indicate that for Ra, the values of FR play significant role. It I also revealed that the overall values of Ra decreases with the increase in SS and DOC and increases with the increment in FR.

- For MRR, the significant and most dominating parameters are the FR and DOC for high rate of removal.

\section{Declarations:}

- Availability of data and materials

The datasets used and/or analyzed during the current study are available from the corresponding author on reasonable request.

\section{- Competing interests}

The authors declare that they have no competing interests 


\section{- Funding}

Not Applicable

- Authors' contributions

All authors have main contribution in experimental data collection, their analysis and in manuscript writing. All authors read and approved the final manuscript

- Acknowledgements

Not Applicable

\section{References}

[1] J.D. Thiele, S.N. Melkote, Effect of cutting edge geometry and work piece hardness on surface generation in the finish hard turning of AISI 52100 steel, J. Mater. Process. Technol. 94 (1999) 216-226.

[2] P.V.S. Suresh, P.V. Rao, S.G. Deshmukh, A genetic algorithmic approach for optimization of surface roughness prediction model, Int. J. Mach. Tools \& Manuf. 42 (2002) 675-680.

[3] J.P. Davim, A note on the determination of optimal cutting conditions for surface finish obtained in turning using design of experiments, J. Mater. Process. Technol. 116 (2001) 305-308.

[4] C.X. (Jack) Feng, X. Wang, Development of empirical models for surface roughness prediction in finish turning, Int. J. Adv. Manuf.Technol. 20 (2002) 348-356.

[5] B.Y. Lee, S.F. Yu, H. Juan, The model of surface roughness inspection by vision system in turning, Mechatronics 14 (2004) 129-141.

[6] E.D. Kirby, Z. Zhang, J.C. Chen, J. Chen, Optimizing surface finish in a turning operation using the Taguchi parameter design method, Int. J.Adv. Manuf. Technol. 30 (2006) 0211029. doi 10.1007/s00170-005-0156-0.

[7] T.S. Lan, M.Y. Wang, Competitive parameter optimization of multiquality CNC turning, Int. J. Adv. Manuf. Technol. 41 (2009) 820-826.doi 10.1007/s00170-008-1495-4.

[8] N.C. Tsourveloudis, Predictive modeling of the Ti6Al4V alloy surface roughness, J. Int. Robot Syst. 60 (2010) 513-530. doi 10.1007/s10846-010-9427-6.

[9] Dmello, Grynal \& Pai, P. \& Puneet, N.P. \& Fang, Ning. (2016). Surface roughness evaluation using cutting vibrations in high speed turning of Ti-6Al-4V - an experimental 
approach. International Journal of Machining and Machinability of Materials. 18. 10.1504/IJMMM.2016.076281.

[10] S. Sakthivelu, M. Meignanamoorthy, M. Ravichandran \& M. Kumar. Effect Of Machining Parameters On Surface Roughness And Material Removal Rate In CNC End Milling. International Journal of Scientific Research and Engineering Studies (IJSRES) Volume 2 Issue 4, April 2015 ISSN: 2349-8862.

[11] Lmalghan, R., Rao M C, K., S, A. et al. Machining Parameters Optimization of AA6061 Using Response Surface Methodology and Particle Swarm Optimization. Int. J. Precis. Eng. Manuf. 19, 695-704 (2018) doi:10.1007/s12541-018-0083-2

[12] M. Naga Phani Sastry, K. Devaki Devi, K. Madhava Reddy. Analysis and Optimization of Machining Process Parameters Using Design of Experiments. Industrial Engineering Letters ww.iiste.org ISSN 2224-6096 (Paper) ISSN 2225-0581 (online) Vol 2, No.9, 2012

[13] J. Eduardo Ribeiro, M. BrazCésar, H. Lopes. Optimization of machining parameters to improve the surface quality. 2nd International Conference on Structural Integrity, ICSI 2017, 4-7 September 2017, Funchal, Madeira, Portuga

[14] Agrawal, Saurabh \& Gaur, M. \& Kasdekar, Dinesh \& Agrawal, Sharad. (2018). Optimization of machining parameters of hard porcelain on a CNC machine by Taguchiand RSM method. International Journal of Engineering, Science and Technology. Vol 10 No.1 2018, pp. 13-22.

[15] Zain AM, Haron H, Sharif S (2011). Estimation of the minimum machining performance in the abrasive waterjet machining using intergrated ANN-SA, Expert Syst Appt 38;83168326.

[16] Hazir, E. \& Ozcan, T. "Response Surface Methodology Integrated with Desirability Function and Genetic Algorithm Approach for the Optimization of CNC Machining Parameters". Arabian Journal for Science and Engineering. March 2019, Volume 44, Issue 3, pp 2795-2809.

[17] Jabir Mumtaz, Zhang Li , Muhammad Imran , Lei Yue, Mirza Jahanzaib , Shoaib Sarfraz, Essam Shehab, Sikiru Oluwarotimi Ismail5 and Kaynat Afzal. Multi-objective optimisation for minimum quantity lubrication assisted milling process based on hybrid response surface methodology and multi-objective genetic algorithm. Advances in Mechanical Engineering 2019, Vol. 11(4) 1-13. 
[18] Zain AM, Haron H, Sharif S (2012). Integrated ANN-GA for estimating the minimum value for machining performance. Int. J. Prod. Res. 50(1): 191-213.

[19] Fedai, Yusuf \& Kahraman, Funda \& Kırlı Akın, Hediye \& Başar, Gökhan. (2018). Optimization of machining parameters in face milling using multi-objective Taguchi technique. Tehnički glasnik. 12. 104-108. 10.31803/tg-20180201125123.

[20] Eun Jung Kim and Choon Man Lee. A Study on the Optimal Machining Parameters of the Induction Assisted Milling with Inconel 718. Materials- 2019, 12(2), 233. 
Figures

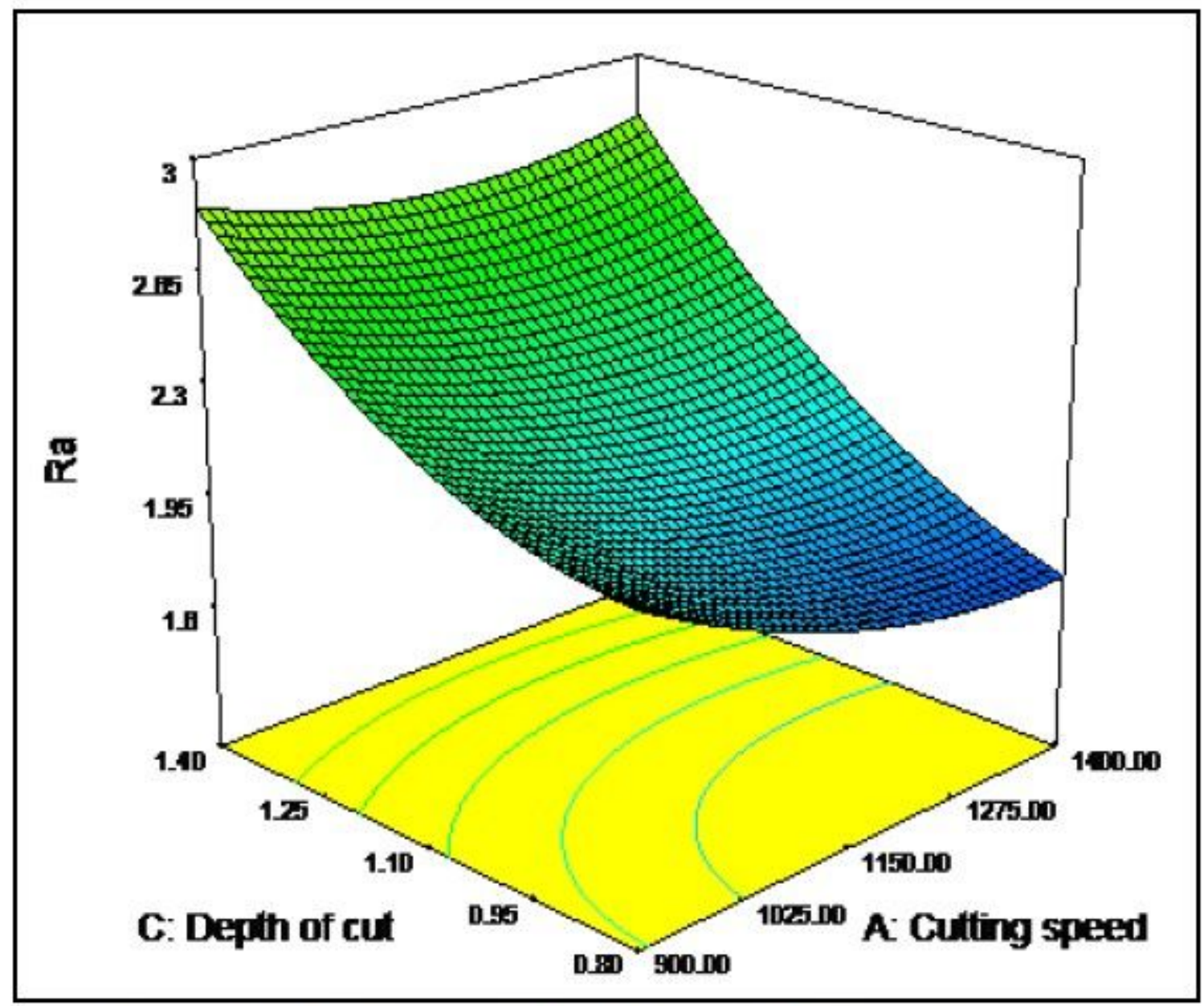

Fig. 1: Effect of DOC and SS on Ra

Figure 1

Effect of DOC and SS on Ra 


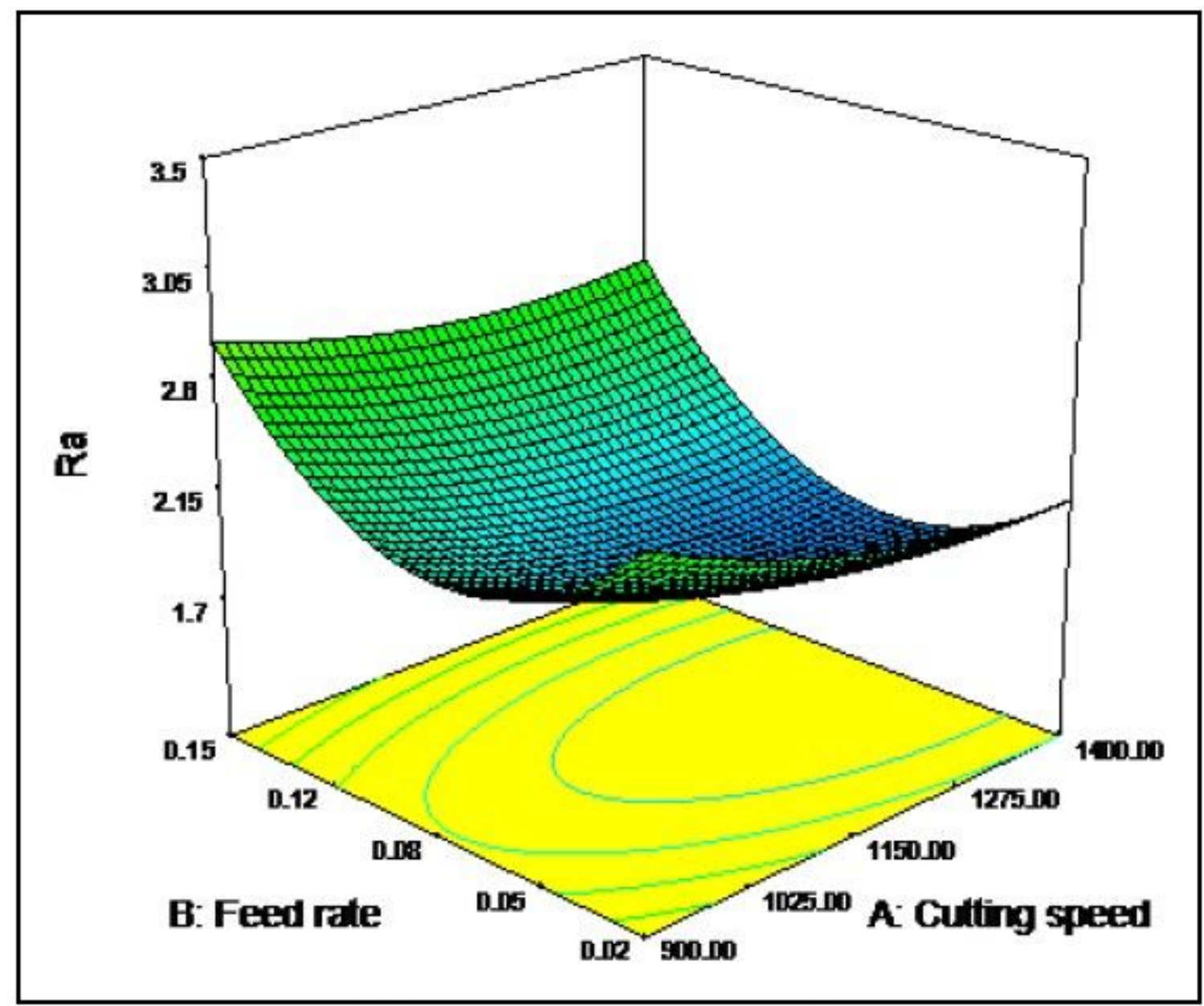

Fig. 2: Effect of FR and SS on Ra

Figure 2

Effect of FR and SS on Ra 


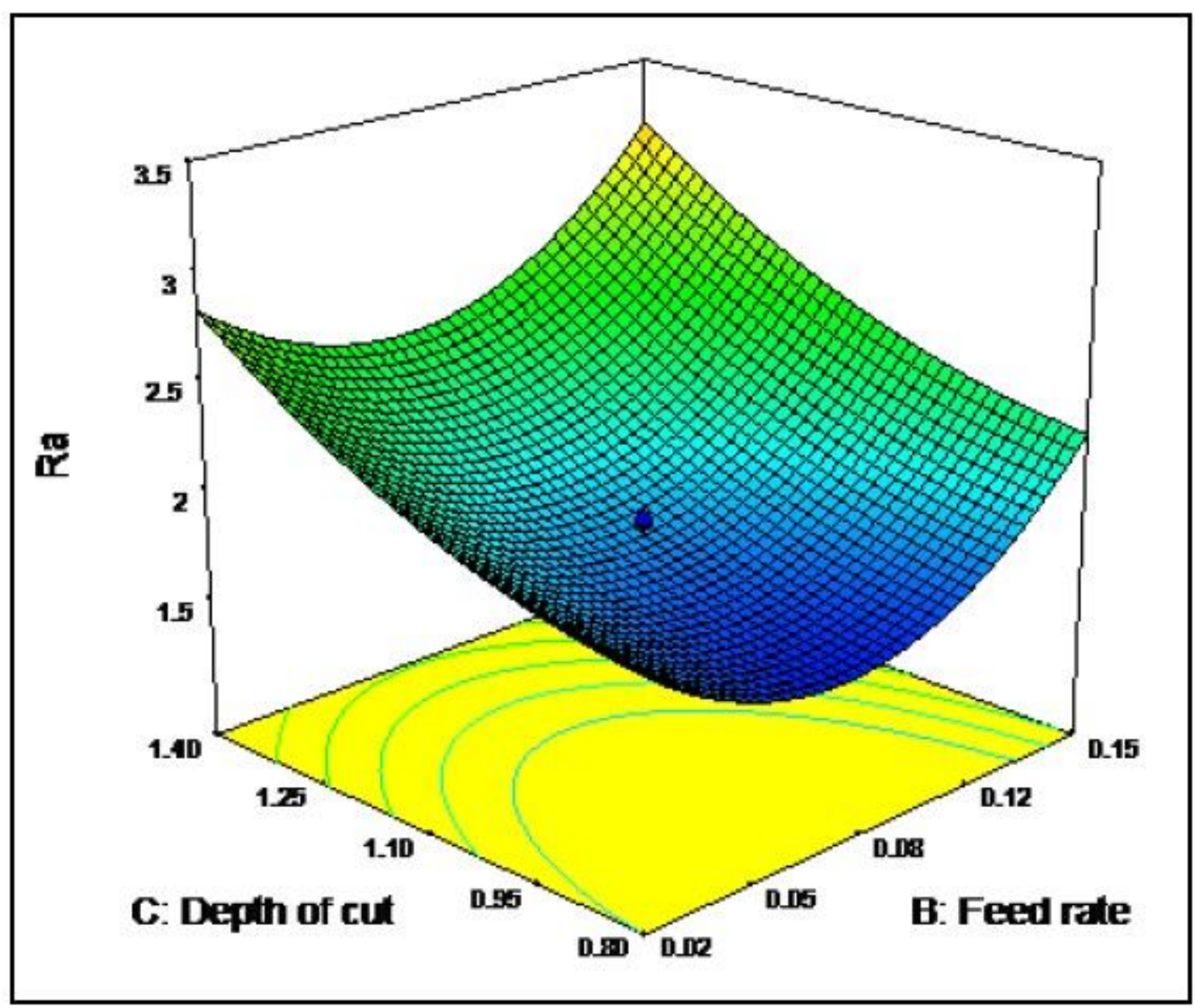

Figure 3

Effect of DOC and FR on Ra 


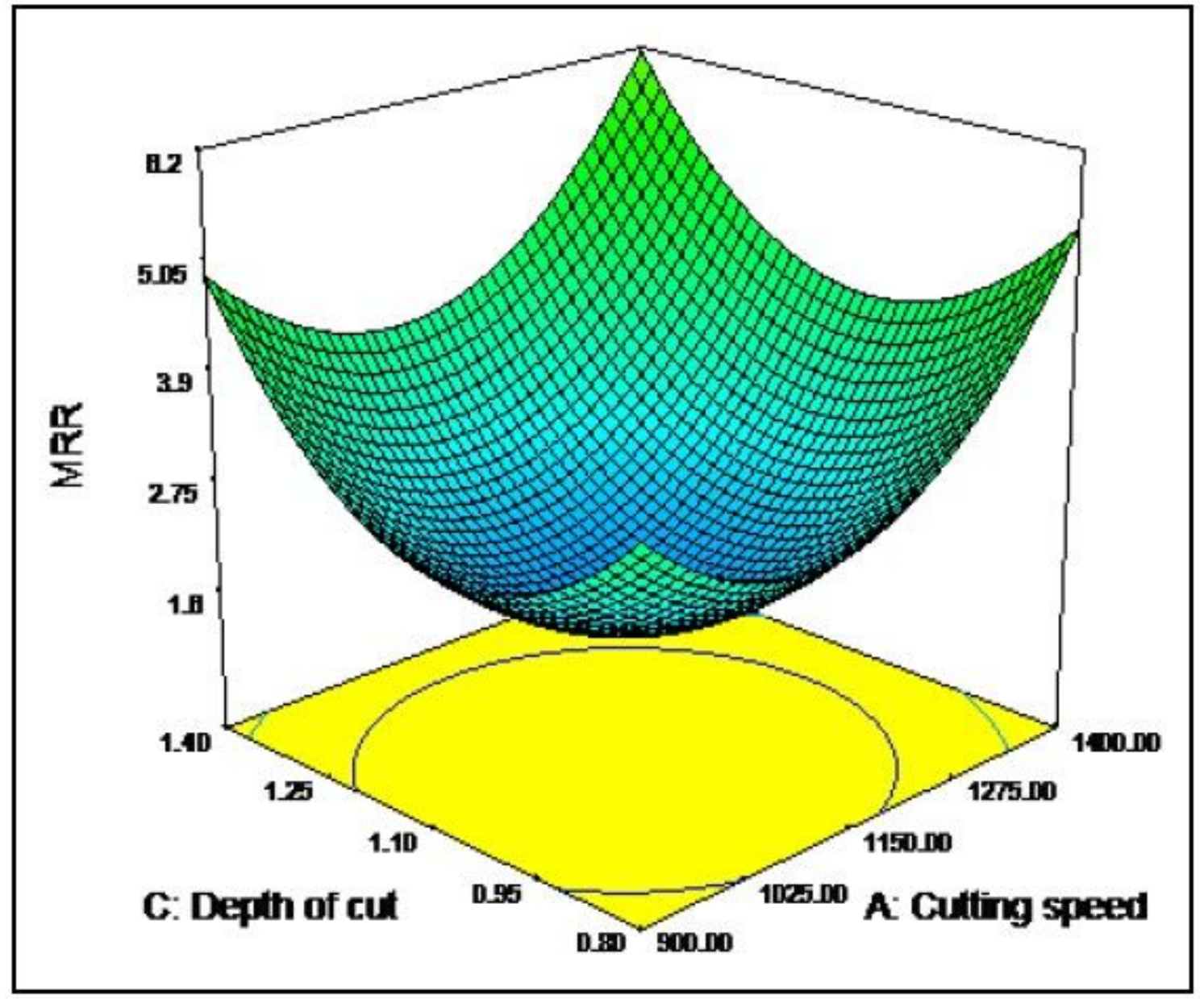

Figure 4

Effect of DOC and SS on MRR 


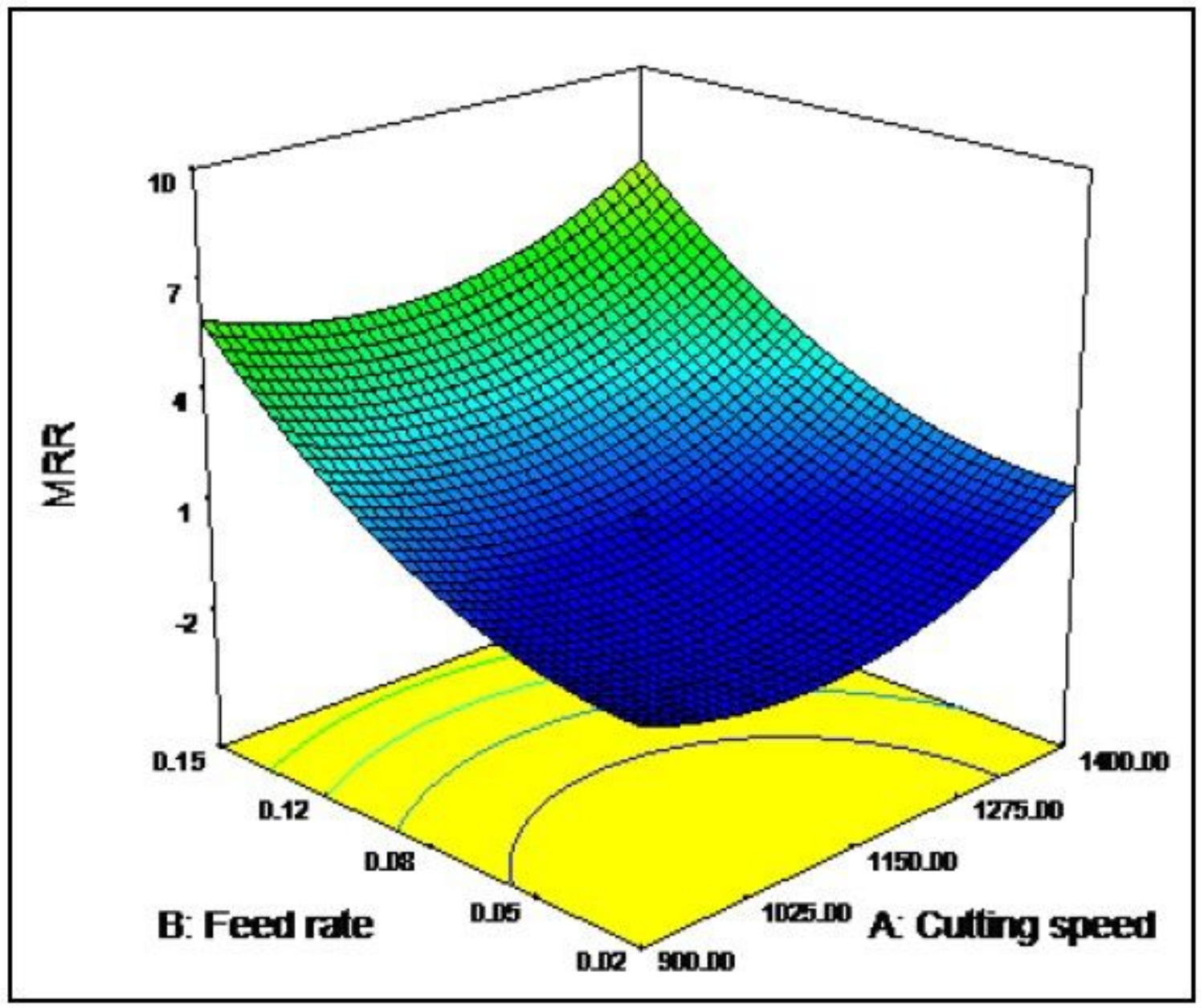

Figure 5

Effect of FR and SS on MRR 


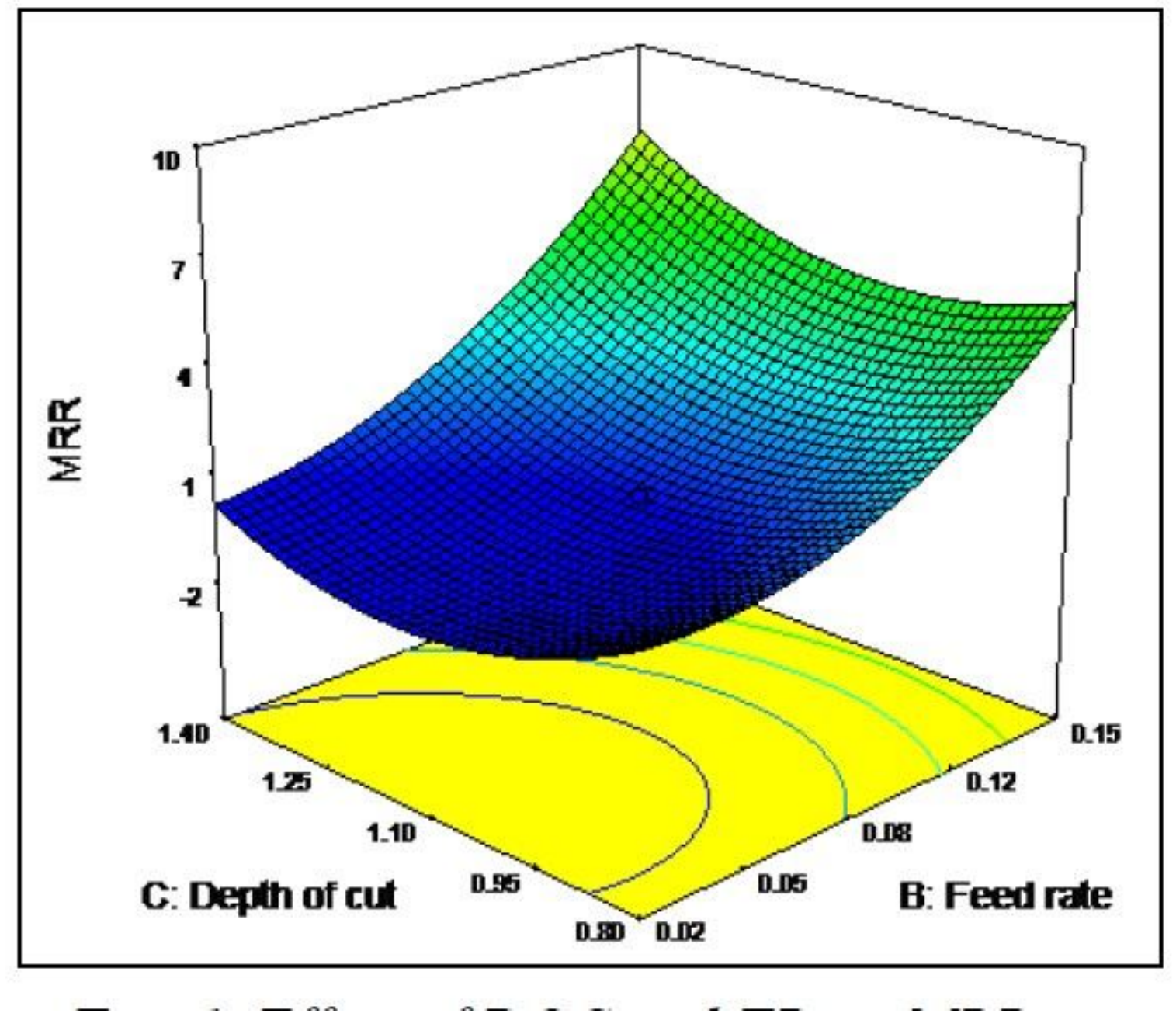

Figure 6

Effect of DOC and FR on MRR 


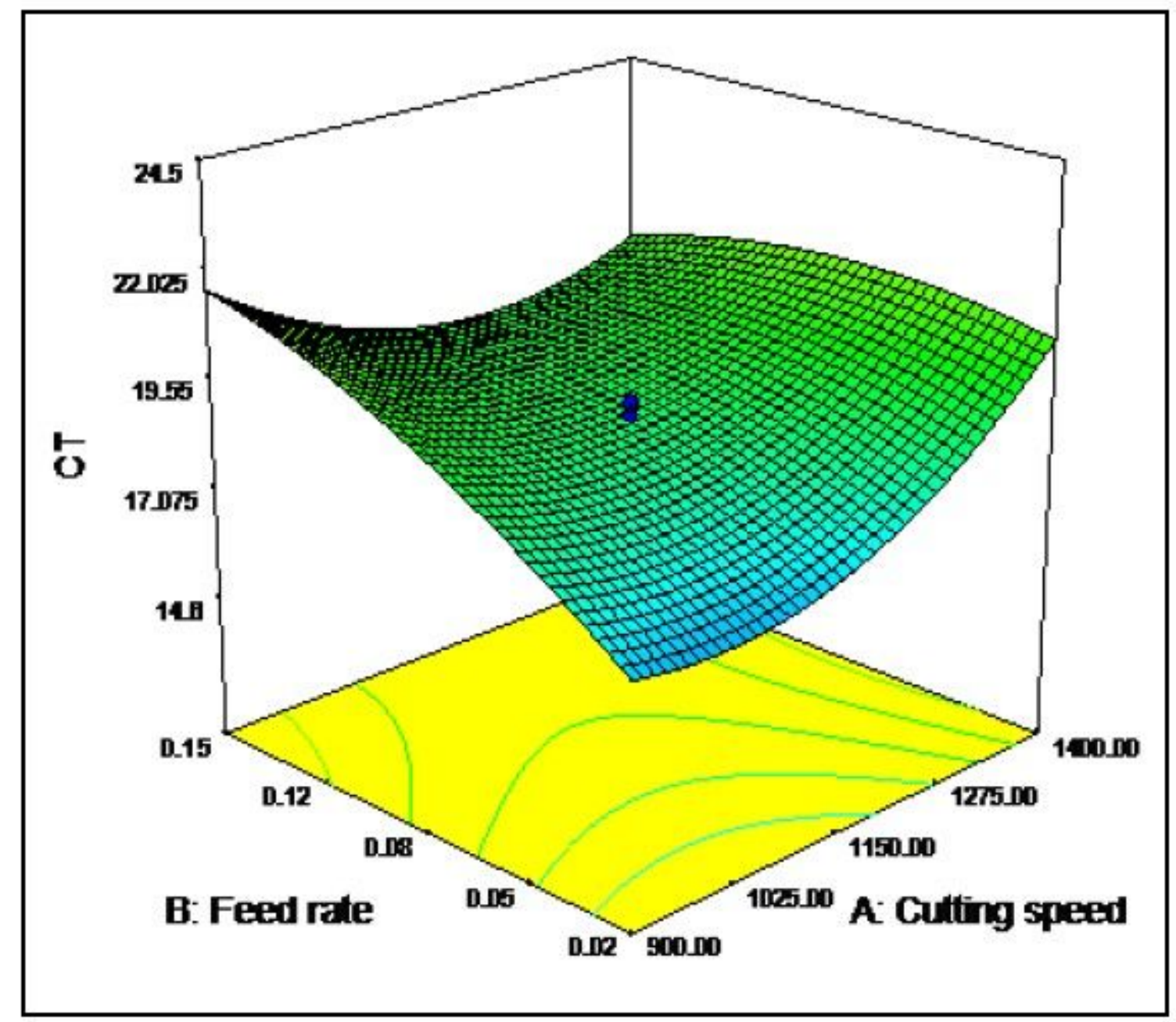

Figure 7

Effect of FR and SS on Tc 


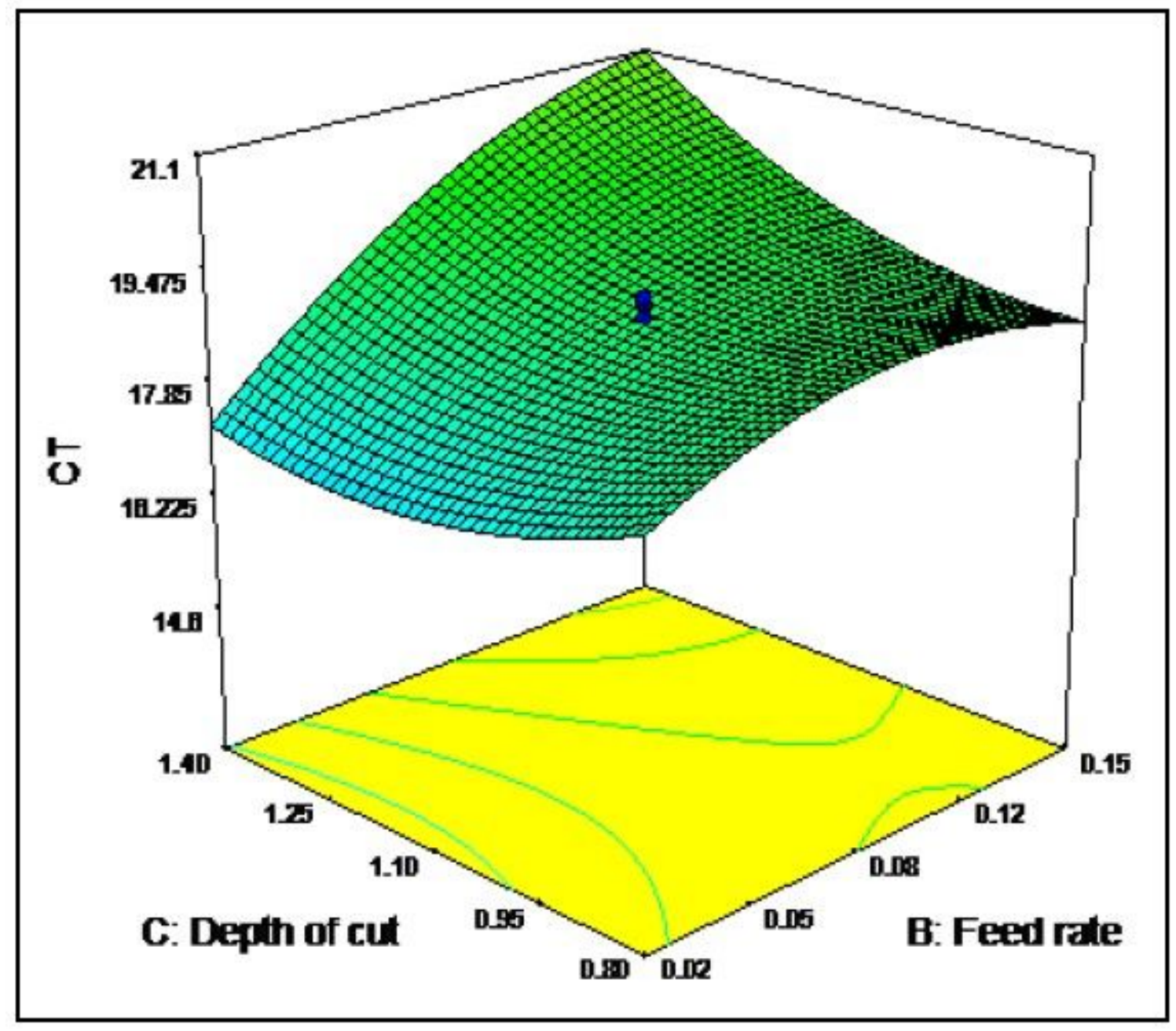

Figure 8

Effect of DOC and FR on TC 


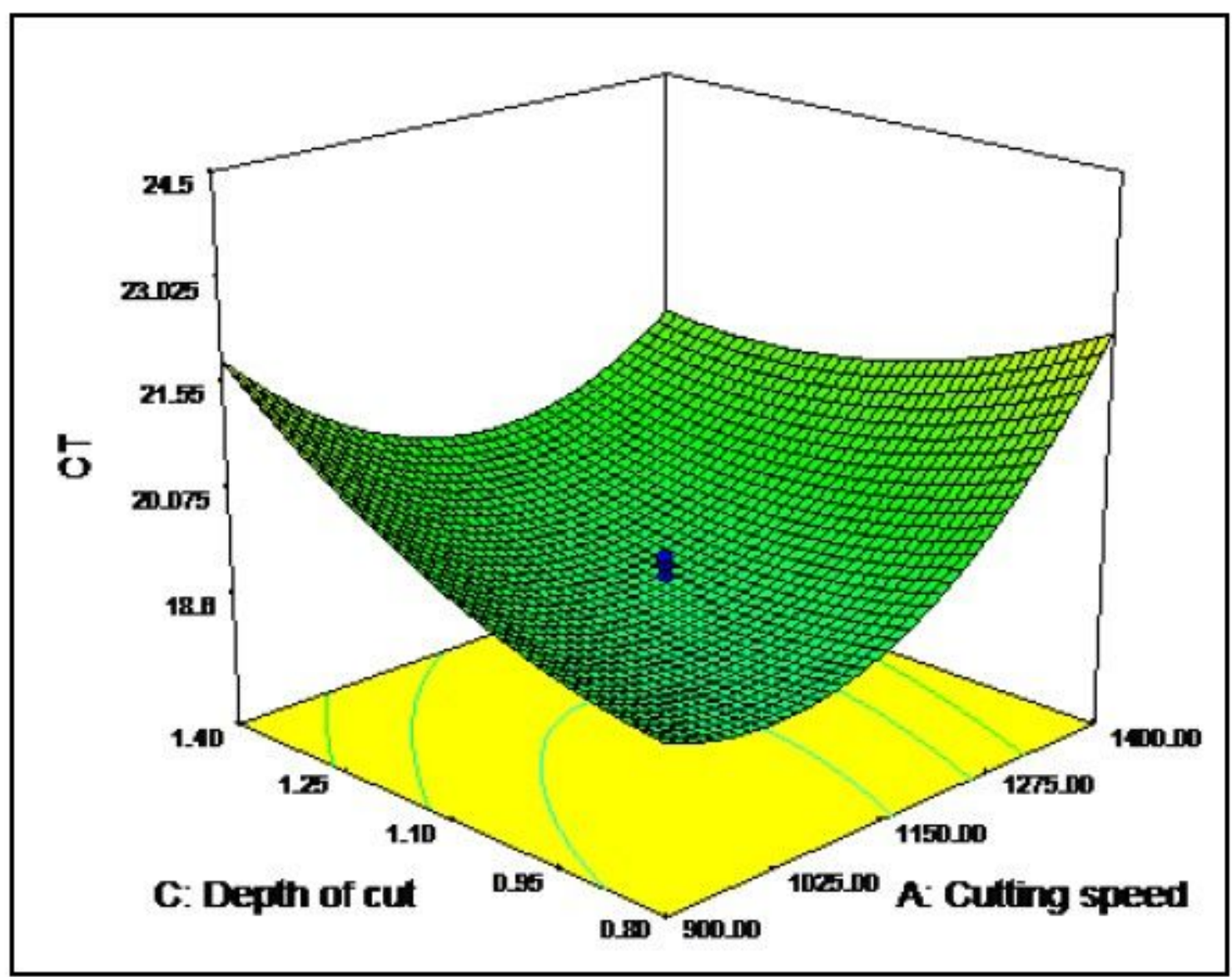

Figure 9

Effect of DOC and FR on TC 